\title{
STUDI KEANDALAN SISTEM KELISTRIKAN KAPAL MENGGUNAKAN METODE FAULT TREE ANALYSIS
}

\begin{abstract}
Rukmini
Program Studi Teknika, Politeknik Ilmu Pelayaran Makassar email: rukmini@pipmakassar.ac.id

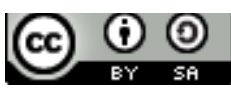

Abstract

Penelitian ini bertujuan untuk mengetahui komponen dan peralatan kelistrikan yang rawan terjadi gangguan atau kerusakan serta kemampuan sistem kelistrikan dalam menjalankan fungsinya di kapal. Untuk menjawab perumusan masalah mengenai komponen/peralatan kelistrikan yang rawan terjadi gangguan atau kerusakan serta kemampuan sistem kelistrikan dalam menjalankan fungsinya di kapal yang dalam hal ini sebagai obyek studi yaitu KM. Bukit Siguntang maka digunakan teori keandalan melalui metode FTA (Fault Tree Analysis). Dari hasil analisis data menghasilkan dengan metode FTA didapatkan yaitu komponen \{1\} Prime Mover, \{2\} Generator, \{3\} Instalasi, \{4\} Pengaman, dimana setiap komponen ini jika terjadi gangguan kerja akan menyebabkan gangguan kerja pada sistem kelistrikan tersebut. Untuk nilai fungsi reliability 0,782 dengan MTTF (Mean Time to Failure) sistem sebesar 1333 jam dengan peluang sistem tersebut menjalankan fungsinya sebesar $78,2 \%$. Namun untuk menjaga agar reliability tetap tinggi (90,3\%) sebaiknya dilakukan perawatan setiap 550 jam operasi.
\end{abstract}

Keywords: Keandalan, Sistem Kelistrikan Kapal, Fault Tree Analysis.

\section{PENDAHULUAN}

Keandalan sistem kelistrikan sangat penting untuk menjamin kontinuitas serta keamanan penggunaan daya listrik. Keandalan sistem kelistrikan dapat dinilai dari kemampuan sistem tersebut untuk tetap menyuplai listrik saat terjadi gangguan di sistem dengan cara membatasi gangguan. Perlunya ketersediaaan supply energi listrik di kapal serta pengoperasiannya yang terjamin, meminimalkan gangguan dan kerusakan terlebih jika berakibat terganggunya operasi dan keselamatan pelayaran.

Akibat yang ditimbulkan oleh gangguan : (a) Menginterupsi kontinuitas pelayanan daya jika gangguan itu sampai menyebabkan terputusnya suatu rangkaian. (b) Penurunan tegangan yang cukup besar menyebabkan rendahnya kualitas listrik dan akan menghalangi kerja normal peralatan listrik. (c) Pengurangan stabilitas sistem dan menyebabkan jatuhnya generator. (d) Merusak peralatan pada daerah terjadinya gangguan.

Kerusakan kelistrikan kapal adalah salah satu faktor yang masih juga menjadi penyebab Kecelakaan Laut.

Berdasarkan [1] bahwa kerusakan kelistrikan kapal masih juga terjadi (walau tergolong minor), yang diantaranya adalah lampu penerangan tidak berfungsi dan teknologi pendukung fasilitas yang menggunakan energi listrik tidak berfungsi.

Penelitian ini merupakan studi aplikasi analisis keandalan terhadap penanganan peralatan listrik pada kapal. Yang dalam hal ini menjadi objek studi yaitu kapal KM. Bukit Siguntang. Adapun masalah yang akan diselesaikan adalah:

1. Komponen atau peralatan kelistrikan apa saja yang rawan terjadi gangguan atau kerusakan?

2. Bagaimana kemampuan sistem kelistrikan dalam menjalankan fungsinya?

Perlunya menganalisis keandalan suatu sistem khususnya dalam penelitian ini yang dilaksanakan di kapal, adalah agar diperoleh nilai keandalan dari sistem kelistrikan kapal sehingga dapat diberikan penanganan yang lebih optimal untuk kelancaran operasional kapal. Serta membantu operator/crew dan pemilik kapal untuk penanganan terkhusus perawatan peralatan tercakup sistem kelistrikan di kapal.

\section{KAJIAN LITERATUR}

Secara internasional (misalnya: Safety of Life at Sea [SOLAS], IEE Regulation for the Electrical and Electronic Equtpment of Ship) maupun secara nasional (misalnya: Biro Klasifikasi Indonesia volume IV Rules for 
Electrical Installation section 1.A.3) mengatur tentang sistem kelistrikan kapal [2].

Di antaranya bahwa:

- Untuk menjalankan kapal dalam keadaan berpenumpangataupun tidak maka semua peralatan listrik yang diperlukan harus terjamin tidak memakai bantuan dari sumber daya listrik darurat .

- Jaminan dalam berbagai keadaan darurat bagi peralatan listrik untuk keselamatan.

- Jaminan keselamatan penumpang, awak kapal dan kapal itu sendiri terhadap bahaya listrik.

Bentuk sumber daya listrik yang digunakan di kapal yaitu, [3]:

- Sebagai sumber utama daya kapal/pembangkit listrik utama, digunakan generator set.

- Generator set cadangan atau accumulator battery sebagai pembangkit cadangan yang digunakan pada kondisi darurat.

Penggunaan dua macam arus yaitu arus searah dan arus bolak-balik pada sistem kelistrikan kapal. Dikarenakan banyaknya variasi daya

beban maka untuk arus bolak-balik ini mempunyai beberapa variasi tegangan bolakbalik antara lain 440 Volt, 220 Volt, 115 Volt, 110 Volt [4]. Sedangkan tegangan searahnya mempunyai variasi yang antara lainnya 28 Volt, 24 Volt, 12 Volt. Variasi juga pada frekuensi yang digunakan juga mempunyai berbagai macam yaitu $50 \mathrm{~Hz}, 60 \mathrm{~Hz} .400 \mathrm{~Hz}$, tidak hanya terbatas pada tegangan saja.

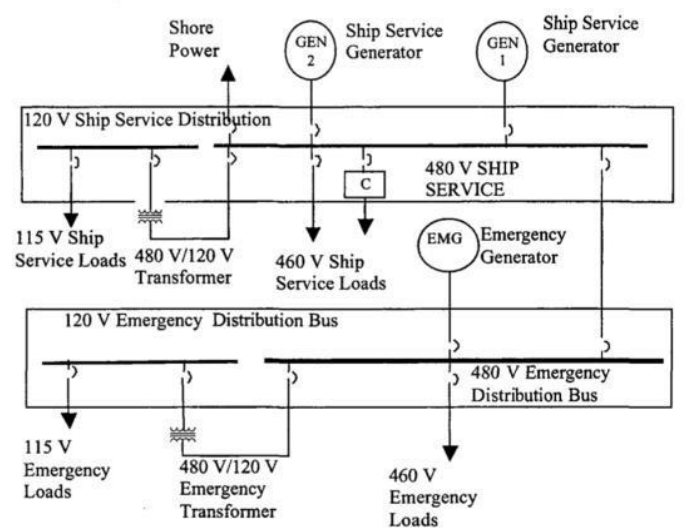

Gambar 1. Diagram Listrik Satu Garis - Pembangkitan dan Distribusi Tenaga Layanan Kapal dengan Dua Generator Layanan Kapal dan Satu Generator Darurat [5] Pada gambar 1 nampak desain terdiri dari satu switchboard layanan kapal dan dua generator layanan kapal. Switchboard darurat dengan satu generator darurat.
- Switchboard layanan kapal_-bagian $480 \mathrm{~V}$

- Pemutus generator

- Pengontrol motor

- Bagian beban layanan kapal untuk mesin bantu, HVAC, mesin dek dan layanan listrik lainnya

- Daya dari/ke darat (pilihan terbuka untuk memberi daya dari layanan kapal atau switchboard darurat)

- Sisi busbar darurat

- Switchboard layanan kapal_-bagian $120 \mathrm{~V}$

- Penerangan

- Layanan 115V lainnya

- $\quad$ Switchboard darurat - bagian $480 \mathrm{~V}$

- Pemutus sirkuit generator darurat

- Beban darurat $480 \mathrm{~V}$

- Sisi busbar darurat ke switchboard layanan kapal

- Switchboard darurat-bagian $120 \mathrm{~V}$

Penerangan darurat dan beban darurat $115 \mathrm{~V}$ lainnya.

Dengan cara meminimalkan kemungkinan

kegagalan, teknik keandalan bertujuan mempelajari konsep, karakteristik, pengukuran, analisis kegagalan dan perbaikan sistem sehingga waktu ketersediaan operasi sistem dapat bertambah [6].

Peluang suatu komponen atau sistem bekerja menurut kebutuhan pada waktu tertentu saat digunakan dalam kondisi beroperasi, adalah makna dari ketersediaan (availability). Peluang bekerjanya komponen atau sistem dalam waktu yang ditentukan sebagai interpretasi ketersediaan.

Peluang suatu komponen atau sistem memenuhi fungsi yang dibutuhkan dalam periode waktu yang diberikan selama digunakan dalam kondisi beroperasi, adalah makna dari keandalan (reliability). Atau dapat pula diartikan bahwa keandalan berarti peluang tidak terjadi kegagalan selama beroperasi.

Kata -reliabilityl terjemahan Indonesianya adalah keandalan, reliable berarti andal. Kadang arti dan makna katanya disamakan dengan kelayakan atau layak (yang berarti feasibility atau feasible).

Namun arti baku dari reliability adalah :

Peluang sebuah komponen, sub-sistem atau sistem melakukan fungsinya dengan baik, seperti yang dipersyaratkan, dalam 


\section{kurun waktu tertentu dan dalam kondisi operasi tertentu pula".}

Karena mengandung komponen peluang, maka secara inheren didalamnya ada masalah statistik termasuk : 1. Uncertainty, 2. Probability, 3. Probability Distributions (Weibull, Normal, Exponensial, Log-normal, dsb).

Karena mengandung komponen -melakukan fungsi dengan baik\|, maka didalamnya secara inheren pula terdapat faktor kegagalan sistem. Sebab peluang kegagalan adalah kebalikan dari peluang keandalannya seperti digambarkan dalam ekspresi matematik (cumulative damage/failure distribution function) berikut :

$$
\mathrm{P}_{\mathrm{f}}(\mathrm{t})=1-\mathrm{R}(\mathrm{t}) \text { atau } \mathrm{R}(\mathrm{t})=1-\mathrm{P}_{\mathrm{f}}(\mathrm{t})
$$

Jadi jika keandalan sebuah sistem adalah $\mathrm{R}$ $=90 \%$, maka peluang kegagalan cumulative nya adalah $\mathrm{P}_{\mathrm{f}}=10 \%$, atau sebaliknya.

Reliability mengandung komponen waktu, artinya sebuah komponen yang reliable sekarang belum tentu reliable satu tahun kemudian jika ada : 1) mekanisme kerusakan yang beroperasi (lloperative damage mechanism\|) dan 2) dengan laju kerusakan tertentu (misalnya laju korosi atau aus 0.01 $\mathrm{mm} /$ year).

Reliability mengandung faktor komponen atau sub-sistem, artinya untuk menguji sebuah sistem yang lebih besar (terdiri dari subsistem atau kompenen), maka reliabilty masingmasing komponen penunjang haruslah dihitung terlebih dahulu baru kemudian dijumlahkan (atau dikalikan) sesuai dengan hubungan seri, paralel (atau keduanya) dengan mengacu pada teori penjumlahan/kombinasi peluang (De Morgan's Rule, Bayes Theorem, dsb). Perhitungan matematika/statistika yang rumit kadang terjadi dalam perumusan teori reliability.

Berbicara reliabilty juga sama artinya dengan berbicara risk (resiko), sebab risk didefiniskan sebagai :

$$
\begin{gathered}
\text { Risk }=\text { Probability of Failure } X \text { Consequency } \\
\text { of Failure }
\end{gathered}
$$

Jadi salah satu komponen risk adalah kebalikan dari reliability (Probability of Failure), oleh sebab itu jika bicara reliability selalu dikaitkan dengan risk.

Untuk jangka waktu tertentu, sejenis peralatan dioperasikan. Pengamatan terus menerus pada kondisi peralatan tersebut. Memiliki dua kemungkinan, yaitu baik atau rusak sebagai kondisi peralatan tersebut pada suatu saat tertentu.

Baik Dapat beroperasi sesuai diinginkan

Rusak Tidak dapat beroperasi yang diinginkan.

Dalam analisa keandalan, kondisi sistem atau peralatan yang beroperasi dalam melaksanakan misinya, dibedakan menjadi dua, yaitu : baik atau rusak. Notasikan kondisi peralatan pada saat $\mathrm{t}$ dengan $\mathrm{x}(\mathrm{t})$. $\mathrm{x}$ adalah variabel acak yang menyatakan kondisi peralatan tersebut.

$\mathrm{x}=1$; jika peralatan tersebut dalam kondisi baik

$\mathrm{x}=0$; jika peralatan tersebut dalam kondisi rusak.

$\mathrm{x}$ merupakan fungsi dari waktu $(\mathrm{x}(\mathrm{t}))$.

$\mathrm{x}(\mathrm{t})=1$; bila pada saat $\mathrm{t}$, peralatan dalam kondisi baik

$\mathrm{x}(\mathrm{t})=0$; bila pada saat $\mathrm{t}$, peralatan dalam kondisi rusak.

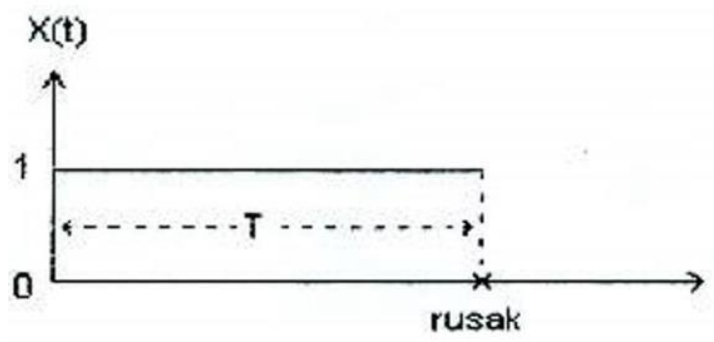

Gambar 2. Masa Pakai Komponen

Dalam keadaan awal $(\mathrm{t}=0)$, diasumsikan peralatan dalam kondisi baik $(\mathrm{x}(0)=1)$

$\mathrm{t}=$ Lamanya peralatan beroperasi sampai mengalami kerusakan atau masa pakai (life time).

Fungsi Keandalan

$$
\mathrm{R}(\mathrm{t})=\mathrm{P}(\mathrm{x}(\mathrm{t}))=1
$$

$\mathrm{R}(\mathrm{t}) \subsetneq$ Keandalan peralatan pada saat $\mathrm{t}, \mathrm{g}$ seringkali disebut sebagai fungsi keandalan.

Fungsi keandalan menyatakan hubungan antara keandalan dengan waktu (yaitu lamanya sistem menjalankan tugas).

\section{Hubungan Perawatan (Maintenance) Peralatan dengan Tingkat Keandalan}

Untuk tujuan agar tidak mengalami penurunan unjuk kerja suatu peralatan atau komponen maka dilakukan suatu usaha secara sadar melalui kegiatan perawatan peralatan dijaga agar tidak mengalami penurunan keandalan. Beberapa tindakan perawatan, yaitu: 
1. Planned Maintenance yaitu suatu tindakan perawatan dimana waktu pelaksanaannya telah direncanakan terlebih dahulu. Kegiatan perawatan yang dapat digolongkan ke dalam planned maintenance system adalah preventive maintenance dan predictive maintenance.

2. Unplanned Maintenance yaitu suatu tindakan perawatan dimana waktu pelaksanaannya tidak direncanakan. Kegiatan perawatan yang dapat digolongkan ke dalam unplanned maintenance adalah corrective maintenance dan breakdown maintenance.

\section{Fault Tree Analysis (FTA)}

Dalam menganalisa keandalan suatu sistem dan komponen secara kualitatif, maka dapat digunakan metode Fault Tree Analysis (FTA). Penentuan penyebab dari suatu peristiwa tertentu yang tidak diinginkan disediakan pada Fault Tree Analysis (FTA) berupa teknik analisis kegagalan deduktif [7], [8], [9].

Penelusuran kembali kemungkinan kesalahan menjadi tujuan pengembangan diagram logis pada analisis kesalahan berjenjang dalam Fault Tree Analysis [10].

-The FTA begins with the definition of an undesirable outcome and pulls together all of the components necessary for that occurrencell [11].

Pada diagram logika dalam Fault Tree Analysis, maka masing-masing dampak dari suatu peristiwa dan kontribusi yang menyebabkan suatu peristiwa terwakili. Diawali dari kejadian yang tidak diinginkan atau kerugian kemudian menganalisa penyebab-penyebabnya menjadi tahap pendekatan yang bersifat -Town-Downl [12].

Analisa berawal dari system level (top) dan meneruskannya ke bawah maka FTA berorientasi pada fungsi atau yang lebih dikenal dengan -top down approach| [6].

Berikut ini merupakan langkah-langkah yang diterapkan dalam menganalisa keandalan listrik kapal yang merupakan suatu sistem [13]:

1. Pendeskripsian Sistem

2. Mendefinisikan setiap fungsi dan kegagalan

3. Fault Tree Analysis

4. Waktu Rata-Rata Kegagalan (Mean Time to Failure/MTTF)

5. Block Diagram Reliability Sistem Seri
Penelitian dengan menggunakan teknik Fault Tree Analysis (FTA) juga pernah dilakukan di antaranya:

1. Analisis Pengendalian Kualitas Dengan Menggunakan Metode Fault Tree Analysis Untuk Meminimumkan Cacat Pada Crank Bed Di Lini Painting PT. Sarandi Karya Nugraha; dikaji oleh Bimo Satriyo, Diana Puspitasari [14]

2. Analisa Penyebab Keterlambatan Proyek Pembangunan Sidoarjo Town Square Menggunakan Metode Fault Tree Analysis, dikaji oleh Ridhati Amalia, Mohammad Arif Rohman, Cahyono Bintang Nurcahyo [15]

3. Siti Rochmana : Perancangan Profil Risiko Dengan Menggunakan Metode FTA Dan FMEA Pada Proses Produksi Pabrik Amdk K3PG [16].

Untuk penelitian ini dilakukan sebagai suatu studi keandalan sistem kelistrikan di kapal dengan teknik analisis terhadap gangguan yang terjadi berdasarkan tingkat keseringannya beserta kondisi yang menjadi penyebabnya. Dimana kita ketahui bahwa sistem kelistrikan kapal merupakan isolated power systems. Sistem tersebut mirip dengan power system pada pesawat, kilang minyak lepas pantai, atau emergency power system pada bank, rumah sakit dan sebagainya.

Apa yang unik dari power system di kapal? Jawaban sederhananya adalah, sistem tenaga listrik yang dipasang pada obyek yang bergerak. Sehingga kontrol operasionalnya meliputi suplai listrik (generator) sekaligus distribusi listrik ke beban.

Untuk itu apabila terjadi gangguan kualitas daya pada kelistrikan kapal menjadi masalah yang sangat serius, terlebih apabila gangguan terjadi saat kapal berlayar di tengah laut dan mengganggu kinerja peralatan control navigasi, motor listrik atau instrumen proteksi kelistrikan kapal.

\section{METODE PENELITIAN}

Pengambilan data penelitian ini dilakukan pada salah satu kapal penumpang milik PT. PELNI yaitu KM. Bukit Siguntang. Pengambilan data efektif dilakukan selama 10 hari. 
Penelitian ini bersifat deskriptif dengan pendekatan observasional. Data yang

digunakan adalah data primer dan data sekunder. Data yang telah dikumpulkan, ditabulasi dan disusun kemudian dianalisa

dengan menggunakan teori

reliabilitas/keandalan.

Adapun data-data yang diambil selama penelitian adalah : (1) beberapa jenis gangguan/kerusakan kelistrikan. (2) frekwensi kejadian gangguan. (3) penyebab kerusakan.

Data tersebut meliputi : (1) Prime Mover. (2) Sumber daya listrik (generator). (3) Sistem instalasi. (4) Pengaman

Langkah-langkah yang diterapkan dalam menganalisa keandalan listrik kapal yang merupakan suatu sistem adalah :

(a) Pendeskripsian Sistem

Dengan tujuan untuk menganalisa keandalan, maka definisi sistem adalah hal yang mutlak dilakukan. Pada point ini, yang dimaksud adalah mendefinisikan setiap sistem yang terdapat di dalamnya.

(b) Mendefinisikan setiap fungsi dan kegagalan

Apabila pemilihan sistem telah dilakukan dan telah didefinisikan batasan-batasan sistem yang akan dianalisa, langkah selanjutnya adalah mengidentifikasi secara detail sistem tersebut yang diperlukan untuk membuat langkah secara cermat dan teliti.

(c) Fault Tree Analysis

TOP event, mengawali pengkonstruksian fault tree. Oleh karena itu, berbagai fault event yang terjadi secara langsung, penting dan berbagai penyebab terjadinya TOP event harus diidentifikasi secara teliti.

Berbagai penyebab dikoneksikan ke TOP event oleh sebuah gerbang logika. Penting kiranya bahwa penyebab level pertama di bawah TOP event harus disusun secara terstruktur. Level pertama ini sering disebut dengan TOP structure dari sebuah fault tree.

(d) Waktu Rata-Rata Kegagalan (Mean Time to Failure/MTTF)

Dalam situasi praktis MTTF digunakan untuk menilai kualitas dan kegunaan suatu komponen. Serta dapat didefinisikan sebagai :

\section{( ) $\int()$}

(4)

eksponensial akan diperoleh [6]:

Dimana $f(t)$ adalah fungsi yang menunjukkan frekuensi gangguan atau kegagalan. Lamda ( ) adalah berbanding terbalik dengan frekuensi.

(e) Block Diagram Reliability Sistem Seri

Analisis keandalan untuk sistem-sistem sederhana dapat dilakukan dengan menggabungkan model keandalan sistem seri, paralel aktif dan stand by. Namun pada penelitian ini, model keandalan yang digunakan adalah sistem seri karena setiap komponen yang mengalami kegagalan maka akan langsung mempengaruhi kinerja sistem tersebut.

\section{HASIL DAN PEMBAHASAN}

a. Hasil Penelitian

1) Deskripsi Kapal

Nama $\quad$ KM. Bukit Siguntang

Galangan $\quad$ : Jos.L.Meyer.Papenburg.Germany
Pembuat

Tahun

Pembuatan

: 1995

Pelabuhan

Registrasi

: Palembang (skr Jakarta)

Kapasitas
Penumpang 2003 Penumpang

Sebagai kapal pembanding dalam studi ini adalah kapal tanker MT.EN VOYAGER (Singapura) (kapasitas 5000 Ton) dengan nahkoda Capt.Deur Sikku dan KKM Tajuddin. Menurut hasil pengamatan di kapal maka sistem kelistrikan kapal tersebut terbagi : Sumber daya (Generator set), instalasi, beban yang meliputi : crane-penerangan-motor blower-control cargo-engine control roommotor pompa-radio komunikasi-TV/tape. Gensetnya terdiri atas 4 buah dengan masingmasing kapasitas $250 \mathrm{kVA}$. Dan karena sistem kelistrikan yang sederhana ini maka pada kapal 
tidak dilengkapi dengan $\mathrm{ABK} / \mathrm{crew}$ yang

khusus menangani kelistrikan dan 
instrumentasi. Sebagai tambahan yaitu bagian pompa untuk mendorong minyak keluar dari kapal dipergunakan pompa yang menggunakan prime mover motor bakar jadi bukan motor listrik.

Untuk kapal KM.Bukit Siguntang (pembuatan tahun 1995 German) milik PT.Pelni (type 2000 $\mathrm{PS}=$ passenger) maka sistem kelistrikan lebih kompleks dibanding kapal cargo yang bermuatan minyak tadi. Sama halnya kapal cargo maka kapal penumpang KM.Bukit Siguntang milik PT.Pelni juga memiliki fasilitas kelistrikan yang sama bahkan kapal penumpang milik PT.Pelni tersebut lebih kompleks kelistrikannya dibanding kapal cargo MT.En Voyager, hal ini dapat dilihat dari : Sumber daya (Genset) yang berkapasitas $4 \mathrm{x}$ 1000 kVA ditambah dengan 1 emergency generator kapasitas $500 \mathrm{kVA}$. Ruangan yang merupakan beban dari sistem kelistrikan meliputi, dapur-kamar tidur penumpang (kelas ekonomi-3wisata-kelas2 A/B-kelas 1 A/Bawak kapal), mushallah, canteen, ruang makan, Laundry, WC. Secara otomatis maka semakin besar kapasitas sumber daya yang disediakan oleh kapal tersebut maka semakin besar pula kebutuhan beban yang dengan sendirinya semakin kompleks sistem kelistrikan pada kapal tersebut. Untuk mengantisipasi permasalahan kelistrikan di kapal milik PT.Pelni maka perusahaan tersebut mempekerjakan 5 orang khusus di bidang kelistrikan.

Kapal penumpang ini menggunakan empat buah generator set/genset (Brushless A.C Generator) produk Taiyo Electric Co, LTD dengan generator jenis penguat sendiri dengan proses synchronisasi control auto voltage rectifier dan engine speed control, sebagai sumber tenaga listrik. Dengan masing-masing generator berkapasitas maksimum $1000 \mathrm{kVA}$, $400 \mathrm{~V}, 50 \mathrm{~Hz}, 1443 \mathrm{~A}, 4$ pasang kutub, 1500 rpm . Serta terdapat 1 buah emergency generator set (genset) berkapasitas $500 \mathrm{kVA}$, $400 \mathrm{~V}, 50 \mathrm{~Hz}, 700$ A. $1500 \mathrm{rpm}$.

Prime mover yang dipakai adalah jenis motor bakar Diesel dengan menggunakan bahan bakar solar HSD, Merek Daihatsu dengan mesin Type-V 10 cylinder, 1400 HP, Turbocharger. Kendala yang pernah dijumpai adalah gangguan pada nozzle-injector sehingga ada bagian cylinder yang mengalami gagal pembakaran, efek ini mengakibatkan tenaga mesin menurun dan vibrasi, karena shaf mesin dihubungkan ke rotor dari generator maka daya output generator ikut hunting.

Pengoperasian generator set pada kapal KM.Bukit Siguntang disesuaikan dengan kondisi beban pada saat kapal dioperasikan. Bila kapal dalam kondisi sandar di dermaga maka kebutuhan daya listrik relatif kecil dibanding dengan saat sedang berlayar. Lazimnya saat sandar maka kapal hanya mengoperasikan 1 buah genset hal ini berdasarkan pengecekan langsung yakni bebannya berkisat $550 \mathrm{KVA}$ dan saat berlayar akan mengoperasikan 3 buah genset karena bebannya dapat mencapai 2300 KVA. Untuk pengoperasian sinkronisasi generator maka para crew $A B K$ hanya melihat jarum penunjukan beban dari sebuah generator, bila beban sudah mencapai $75 \%$ maka di start 1 generator tambahan dan setelah normal maka generator tambahan tersebut diparalelkan ke generator yang telah berbeban sebelumnya, saat itu beban kedua generator sama rata, begitu selanjutnya. Untuk kondisi beban yang menurun maka kembali para crew ABK memandang beban salah satu generator, apabila telah turun ke $25 \%$ maka akan melepaskan supplai salah satu generator dan menghentikan prime mover nya.

Untuk mengamankan sumber daya, instalasi dan beban maka sistem kelistrikan kapal dilengkapi dengan pengaman. Pengaman terdiri atas ACB/air circuit breaker (untuk mengamankan generator), Over current relay, differential relay-earth fault relay (adalah peralatan proteksi yang bekerja secara otomatis mentripkan ACB bila terjadi gangguan sesuai setting peralatan relay tersebut), TOR/thermal over load relay (untuk mengamankan motor listrik dari beban lebih), MCB/miniatur circuit breaker sebagai pembatas beban lebih sekaligus pengaman terhadap arus hubung singkat pada beban.

Instalasi merupakan jaringan listrik yang menghubungkan sumber daya listrik ke beban, sering dijumpai gangguan kabel terbakar, isolasi terkelupas, basah, peralatan kontak body, terminal pengaman yang terbakar, dan kabel putus yang diakibatkan oleh gigitan binatang penggerat seperti tikus.

2) Pencatatan Gangguan Listrik Kapal Berdasarkan pencatatan order kerja bagian listrik pada kapal KM. Bukit Siguntang, pada pencatatan 8000 jam operasi (Januari 2019 - 
Oktober 2019), secara garis besar terdapat gangguan sebagai berikut :

Tabel 1. Pencatatan Laporan Kerusakan

\begin{tabular}{cccc}
\hline No. & $\begin{array}{c}\text { Sub } \\
\text { Sistem }\end{array}$ & $\begin{array}{c}\text { Frekuensi } \\
\text { Kerusakan }\end{array}$ & $\begin{array}{c}\text { Total Jam } \\
\text { Operasi }\end{array}$ \\
\hline 1. & $\begin{array}{l}\text { Prime } \\
\text { mover }\end{array}$ & 1 & 8000 \\
\hline 2. & Generator & 2 & 8000 \\
\hline 3. & Instalasi & 1 & 8000 \\
\hline 4. & Pengaman & 2 & $\underline{8000}$ \\
\hline \multicolumn{2}{l}{ Sumber : Data Hasil }
\end{tabular}

\section{b. Pembahasan}

Top event kelistrikan pada KM. Bukit Siguntang yang mengalami kegagalan (failure) yaitu gangguan supplai listrik ke beban. Apabila terjadi salah satu kejadian di bawah gerbang Go, mengalami kegagalan yaitu pada basic event (1) Generator mengalami kegagalan, basic event (2) Prime mover mengalami kegagalan, basic event (3) Pengaman mengalami kegagalan, basic event (4) Instalasi mengalami kegagalan pula.

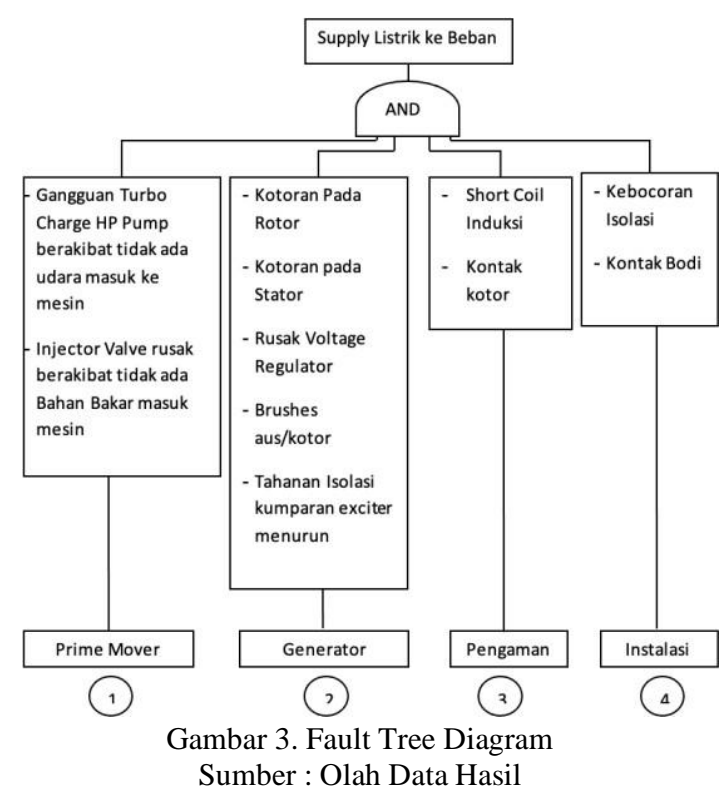

Dari gambar 3, maka dengan jelas dapat ditentukan cut set dari diagram tersebut yaitu : $\{1\},\{2\},\{3\},\{4\}$. Apabila terjadi kegagalan pada salah satu komponen yang terdapat dalam sistem, maka komponen tersebut harus di-repair maupun di-replace.

Adapun komponen-komponen tersebut adalah :

$1=$ Prime Mover

$2=$ Generator
$3=$ Instalasi

4 = Pengaman

1) Reliability Block Diagram

Reliability Block Diagram merupakan gambaran grafis tentang hubungan komponen-komponen yang ada dalam sistem. Rangkaian dasar yang sering dilakukan dalam rangkaian reliability block diagram adalah susunan seri, paralel dan standby. Pengertian standby yakni bila diperlukan maka komponen tersebut membantu rangkaian komponen lain namun bila rangkaian standby dilepas maka tidak mempengaruhi sistem secara keseluruhan. Namun pada objek penelitian ini, rangkaiannya merupakan rangkaian seri dimana hal ini menggambarkan bahwa apabila terdapat salah satu komponen saja yang mengalami kegagalan maka akan menyebabkan kegagalan pada sistem tersebut, dan gambar 2 merupakan RBD dari sistem kelistrikan yang menjadi objek penelitian ini :

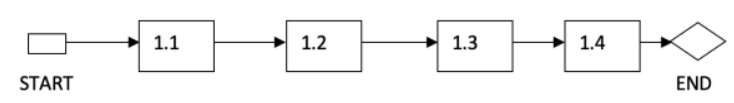

Gambar 4. Reliability Block Diagram Listrik Kapal

Pada gambar 4, menunjukkan sistem kelistrikan yang merupakan objek pada penelitian ini. Pada sub sistem kelistrikan memiliki empat buah komponen dasar yang bekerja dengan konfigurasi seri, yaitu :

1.1. Prime mover, yaitu dalam hal ini berupa motor bakar diesel

1.2. Generator, yaitu pesawat bantu berupa mesin listrik yang mengubah energi mekanik menjadi energi listrik.

1.3. Instalasi, yaitu sistem kelistrikan yang menghubungkan sumber listrik menuju ke beban

1.4. Pengaman, berfungsi mengamankan peralatan, menjaga kontinuitas kelistrikan dan melindungi manusia disekitarnya

Pada Reliability Block Diagram (RBD) di atas, dapat diketahui bahwa pada penyusunan setiap komponen dalam sebuah sistem dilakukan secara seri dimana akan menunjukkan bahwa setiap komponen memegang peranan penting dalam sistem. Yaitu, jika terdapat kegagalan pada salah 
satu komponen dari sistem maupun sub sistem akan menyebabkan kegagalan pada keseluruhan sistem tersebut. Jika komponen-komponen yang ada di dalam sistem itu harus bekerja atau berfungsi seluruhnya agar sistem tersebut sukses dalam menjalankan (misi) fungsinya, maka suatu sistem dapat dimodelkan dengan susunan seri. Atau dengan kata lain sistem itu gagal menjalankan fungsinya bila ada salah satu komponen saja yang tidak bekerja.

Dalam mengevaluasi sistem secara kuantitatif diperlukan data, dimana data tersebut diambil dari data gangguan kelistrikan dan penanganannya serta datadata perawatan dalam rentang waktu mulai dari 1 tahun. Distribusi yang digunakan pada penelitian ini adalah distribusi eksponensial, dengan ciri adalah laju kegagalannya yang konstan. Dari gambar 4 di atas fungsi reliability dapat diturunkan berdasar persamaan di bawah ini:

$$
\begin{array}{r}
R_{S}(t)=1^{e-\int_{0}^{1} \lambda(\mathrm{t}) \mathrm{dt}} \\
R_{S}(t)=\lambda_{1}+\lambda_{2}+\lambda_{3}+\lambda_{4} \\
R_{S}(t)=e^{-(\lambda, \mathrm{t}(\mathrm{d} \mathrm{t}))}
\end{array}
$$

Sehingga Mean Time to failure (MTFF) dimana memiliki konfigurasi seri dengan distribusi eksponensial adalah :

$$
\begin{array}{r}
M T T F=\int_{0}^{\infty} R_{S}(t) d t \\
M T T F=\frac{1}{\lambda_{1}+\lambda_{2}+\lambda_{3}+\lambda_{4}} \\
M T T F=1333 \mathrm{jam}
\end{array}
$$

Dari MTTF di atas dapat disimpulkan bahwa pada jam operasi ke 1333, maka salah satu dari komponen yang terdapat dalam sistem kelistrikan akan mengalami kegagalan yang akan menyebabkan kegagalan sistem kelistrikan sebagai sebuah sistem. Hal ini disebabkan karena setiap komponen memegang peranan yang penting dalam sistem sehingga apabila salah satu komponennya gagal maka keseluruhan komponen juga harus dilakukan perawatan yang preventive untuk mencegah kegagalan yang lebih besar akibat kegagalan komponen yang lainnya. Artinya waktu rata-rata sistem tersebut akan mengalami kegagalan setelah 1333 jam operasi dengan peluang sistem tersebut akan mampu menjalankan fungsinya sebesar 78,2\%.

Waktu Perawatan $=900$ jam dengan $\mathrm{R}(900)=0,846$

Untuk peluang sistem tersebut mampu menjalankan fungsinya sebesar $84,6 \%$ maka pada sistem tersebut harus dilakukan perawatan sebelum mencapai 900 jam operasi.

Waktu Perawatan $=550$ jam dengan

$\mathrm{R}(550)=0,903$

Sedangkan untuk memiliki Reliability yang tinggi (90,3 \%) maka sebaiknya sistem tersebut dilakukan perawatan setiap 550 jam operasi.

Dari RDB dapat diketahui jika sistem kelistikan tersebut merupakan sistem susunan seri sehingga jika terjadi suatu kegagalan komponen di dalamnya maka akan menyebabkan kegagalan generator itu sendiri. Dan dari perhitungan MTTF di atas dapat disimpulkan bahwa pada saat mencapai 1333 jam operasi, maka salah satu dari komponen yang terdapat pada sistem kelistrikan akan mengalami kegagalan yang akan menyebabkan $(21,8 \%)$ kegagalan sistem kelistrikan. Jadi yang akan menjadi point penting pada analisa MTTF ini adalah sistem kelistrikan tersebut dilakukan pemeriksaan dan perawatan paling lambat sebelum 1333 jam operasi. Sebab jika melewati batas waktu tersebut maka sistem akan mengalami kegagalan pada tingkat 21,8 $\%$.

\section{KESIMPULAN}

Untuk studi sistem kelistrikan kapal dengan metode analisis FTA (Fault Tree Analysis) didapatkan yaitu komponen $\{1\}$ Prime Mover, $\{2\}$ Generator, $\{3\}$ Instalasi, $\{4\}$ Pengaman, dimana setiap komponen ini gagal akan menyebabkan kegagalan pada sistem kelistrikan tersebut. Diperoleh nilai fungsi reliability 0,782 dengan MTTF (Mean Time to Failure) sistem sebesar 1333 jam. Artinya, waktu rata-rata sistem tersebut akan mengalami kegagalan setelah 1333 jam dengan peluang sistem tersebut menjalankan fungsinya sebesar $78,2 \%$. Namun untuk menjaga agar reliability tetap tinggi $(90,3 \%)$ sebaiknya dilakukan perawatan setiap 550 jam operasi. 
Disarankan untuk melakukan kegiatan pemeriksaan dan perawatan berkala terhadap komponen kritis serta mendata dengan baik waktu dan jumlah perbaikan maupun kerusakan dalam satu periode tertentu, agar dapat menprediksi perilaku sistem kelistrikan yang ada di atas kapal.

\section{UCAPAN TERIMA KASIH}

Ucapan terima kasih disampaikan kepada Pihak PT. Pelni khususnya Crew Kapal KM. Bukit Siguntang yang telah memberi kesempatan kepada Peneliti untuk mengambil data. Juga kepada Institusi Politeknik Ilmu Pelayaran, atas segala dukungan yang diberikan.

\section{REFERENSI}

[1] Marine Engineer, IMarE Edisi XXXVIII. Sistem Kelistrikan pada Propulsi, Juli 2001.

[2] Biro Klasifikasi Indonesia. -Rules For Electrical Installationl, Vol IV, BKI, Jakarta, 1996.

[3] Listrik Kapal, Proyek Segitiga Biru UNHAS-ITS-UNPATI, 2003.

[4] Watson, George Oliphant. -Marine Electrical Practicell, Butterworth \& Co, London, 1983.

[5] Mohammed M. Islam. Handbook to IEEE Standard 45TM. A Guide to Electrical Installations on Shipboard. The Institute of Electrical and Electronics Engineers, Inc. All rights reserved. Published August 2004.

[6] Priyanta, Dwi. Keandalan dan Perawatan. Teknik Sistem Perkapalan, ITS, Surabaya 2000.

[7] U.S. Nuclear Regulatory Commission. NUREG - 0492: Fault Tree Handbook. Washington, D.C: U.S. Nuclear Regulatory Commission, 1981.

[8] Anthony, R. The Application of Hazard Identification and Risk Analysis (HIRA) And Fault Tree Analysis (FTA) Methods For Controlling Occupational Accidents in Mixing Division Dewi-Dewi Farm Vol. 3 No. 2. Jurnal Ilmiah Teknik Industri, 2015

[9] Richma Yulinda Hanif, dkk. Perbaikan Kualitas Produk Keraton Luxury di PT.X dengan Menggunakan Metode Failure Mode and Effect Analysis (FMEA) dan Fault Tree Analysis (FTA). Jurnal Teknik Industri Itenas (Nomor 03 tahun 2015).

[10] John Ridley. Keselamatan dan Kesehatan Kerja (Ikhtisar) edisi ke-3 (Alih bahasa: Soni Astantro, S.Si). Jakarta: Erlangga, 2008.

[11] James Roughton dan Nathan. Job Hazard Analysis A Guide For Volutary Compliance and Beyond. second edition. US: Elsevier, 2016.

[12] Yusuf Wachyudi. Identifikasi Bahaya, Analisis, dan Pengendalian Risiko Dalam Tahap Desain Proses Produksi Minyak \& Gas Di Kapal Floating Production Storage $\&$ Offloading (FPSO). Untuk Projek Petronas Bukit Tua Tahun 2010. Tesis. Jakarta: Universitas Indonesia.

[13] Zulkifli. Studi Evaluasi Sistem Pendingin Air Tawar dan Pemodelan Perawatan Berbasis Keandalan(Reliability), Tesis Program Pascasarjana, ITS, 2001.

[14] Bimo Satriyo, Diana Puspitasari. Analisis Pengendalian Kualitas Dengan Menggunakan Metode Fault Tree Analysis Untuk Meminimumkan Cacat Pada Crank Bed Di Lini Painting PT. Sarandi Karya Nugraha, Program Studi Teknik Industri, Fakultas Teknik, Universitas Diponegoro, 2015.

[15] Ridhati Amalia, Mohammad Arif Rohman, Cahyono Bintang Nurcahyo. Analisa Penyebab Keterlambatan Proyek Pembangunan Sidoarjo Town Square Menggunakan Metode Fault Tree Analysis (FTA) Jurusan Teknik Sipil, Fakultas Teknik Sipil Dan Perencanaan, Institut Teknologi Sepuluh Nopember (ITS) Jurnal Teknik ITS Vol. 1, No. 1, (Sept. 2012).

[16] Siti Rochmana. Perancangan Profil Risiko Dengan Menggunakan Metode FTA Dan FMEA Pada Proses Produksi Pabrik AMDK K3PG. Fakultas Teknologi Industri Institut Teknologi Sepuluh Nopember Surabaya 2017. 